Добони А.А. ${ }^{1}$

${ }^{1}$ Санкт-Петербургский государственный университет

\title{
Частные торговые марки: восприятие, роль и стратегические перспективы развития в современных условиях
}

\author{
АННОТАЦИЯ: \\ В статье представлены основные тренды современной экономики в части развития \\ розничного рынка и рынка FMCG-продукции. Обоснована изменившаяся роль \\ крупнейших розничных торговых сетей (ритейлеров) в сегменте реализации FMCG- \\ продукции. Уточнена роль частных торговых марок в стратегии развития крупнейших \\ ритейлеров России. Выявлены основные тенденции развития частных торговых марок как \\ на зарубежных рынках, так и на российском FMCG-рынке. Обоснованы стратегические \\ перспективы развития частных торговых марок в России. \\ КЛЮЧЕВЫЕ СЛОВА: частные торговые марки; тенденции; собственные торговые \\ марки; розничный ритейл; FMCG-рынок; розничные сети \\ JEL: L11, L66, L81 \\ ДЛЯ ЦИТИРОВАНИЯ: \\ Добони, А.А. (2015). Частные торговые марки: восприятие, роль и стратегические \\ перспективы развития в современных условиях. Торгово-экономический журнал, 2(1), \\ 19-30. doi: $\underline{10.18334 / \text { tezh.2.1.233 }}$
}

Добони Артем Александрович, аспирант кафедры экономики предприятия и предпринимательства Санкт-Петербургского государственного университета (regionagts@mail.ru)

ПОСТУПИЛО В РЕДАКЦИЮ: 03.03.2015 / ОПУБЛИКОВАНО: 30.03.2015

ОТКРЫТЫЙ ДОСТУП: http://dx.doi.org/10.18334/tezh.2.1.233

(с) Добони А.А. / Публикация: ООО Издательство "Креативная экономика"

Статья распространяется по лицензии Creative Commons CC BY-NC-ND (http://creativecommons.org/licenses/by-nc-nd/3.0/)

ЯЗЫК ПУБЛИКАЦИИ: русский

Metadata in English is available.

For detailed information, please, visit http://dx.doi.org/10.18334/tezh.2.1.233 


\section{Современное состояние ключевьх показателей национальной экономики и роль розничной торговли на нынешнем этапе развития}

Как известно, одной из главных целей любой национальной политики является повышение качества жизни населения и его благосостояния. При этом существуют экономические количественные индикаторы (уровень ВВП на душу населения, уровень доходов, объемы потребительского рынка и др.), позволяющие определить степень достижения этой цели. Последние годы развития российской экономики характеризовались ростом ряда макроэкономических показателей взаимообусловленных и взаимосвязанных друг с другом, - которые наглядно демонстрируют наличие существенных подвижек в повышении косвенных показателей, влияющих на качество жизни населения страны (табл. 1).

Таблица 1

Динамика ключевых макроэкономических показателей России за 2005-2014 гг. ${ }^{1}$

\begin{tabular}{|l|c|c|c|c|c|c|}
\hline \multicolumn{1}{|c|}{ Показатель } & $\begin{array}{c}2005 \\
\text {. }\end{array}$ & $\begin{array}{c}2010 \\
\text { 2. }\end{array}$ & $\begin{array}{c}2011 \\
\text { 2. }\end{array}$ & $\begin{array}{c}2012 \\
\text { 2. }\end{array}$ & $\begin{array}{c}2013 \\
\text { 2. }\end{array}$ & $\begin{array}{c}2014 \\
\text {. . }\end{array}$ \\
\hline ВВП, трлн руб. & 21,6 & 46,3 & 56,0 & 62,1 & 66,2 & 71,0 \\
\hline Численность населения, млн чел. & 143,8 & 142,8 & 142,9 & 143,0 & 143,3 & 143,7 \\
\hline ВВП на душу населения, тыс. руб. & 150,3 & 324,3 & 391,7 & 434,6 & 461,9 & 493,9 \\
\hline $\begin{array}{l}\text { Естественный прирост (+), убыль (-) } \\
\text { населения, тыс. чел. }\end{array}$ & $-287,7$ & $-81,7$ & $-42,4$ & $-6,3$ & $-0,8$ & 24,9 \\
\hline $\begin{array}{l}\text { Среднемесячная номинальная } \\
\text { начисленная заработная плата } \\
\text { работников организаций, тыс. руб. }\end{array}$ & 8,6 & 21,0 & 23,4 & 26,6 & 29,8 & 35,3 \\
\hline $\begin{array}{l}\text { Объем отгруженных товаров } \\
\text { собственного производства, трлн руб. }\end{array}$ & 13,6 & 28,8 & 35,1 & 38,2 & 41,4 & 43,4 \\
\hline $\begin{array}{l}\text { Продукция сельского хозяйства, } \\
\text { трлн руб. }\end{array}$ & 1,4 & 2,6 & 3,3 & 3,3 & 3,7 & 4,2 \\
\hline
\end{tabular}

В свою очередь, значительная динамика ключевых макроэкономических показателей обусловливает рост потребления во всех значимых сегментах экономики и, главным образом, в контексте

\footnotetext{
${ }^{1}$ Составлено по данным сайта Федеральной службы государственной статистики: Валовой внутренний продукт в текущих ценах (1995-2014 гг.); Численность населения; Среднемесячная номинальная начисленная заработная плата работников организаций по видам экономической деятельности; Объем отгруженных товаров собственного производства, выполненных работ и услуг собственными силами по отдельным видам экономической деятельности Российской Федерации; Продукция сельского хозяйства по категориям хозяйств
} 
задач данной статьи - на розничном рынке продовольственной продукции. Так, за последние 10 лет (рис. 1), как совокупный оборот розничной торговли вырос в 3,7 (или 270,9\%) раза, а объем розничной торговли в пересчете на душу населения в 3,5 (или 250\%) раза (что несколько отстает от роста других макроэкономических показателей, в частности, средних доходов населения).

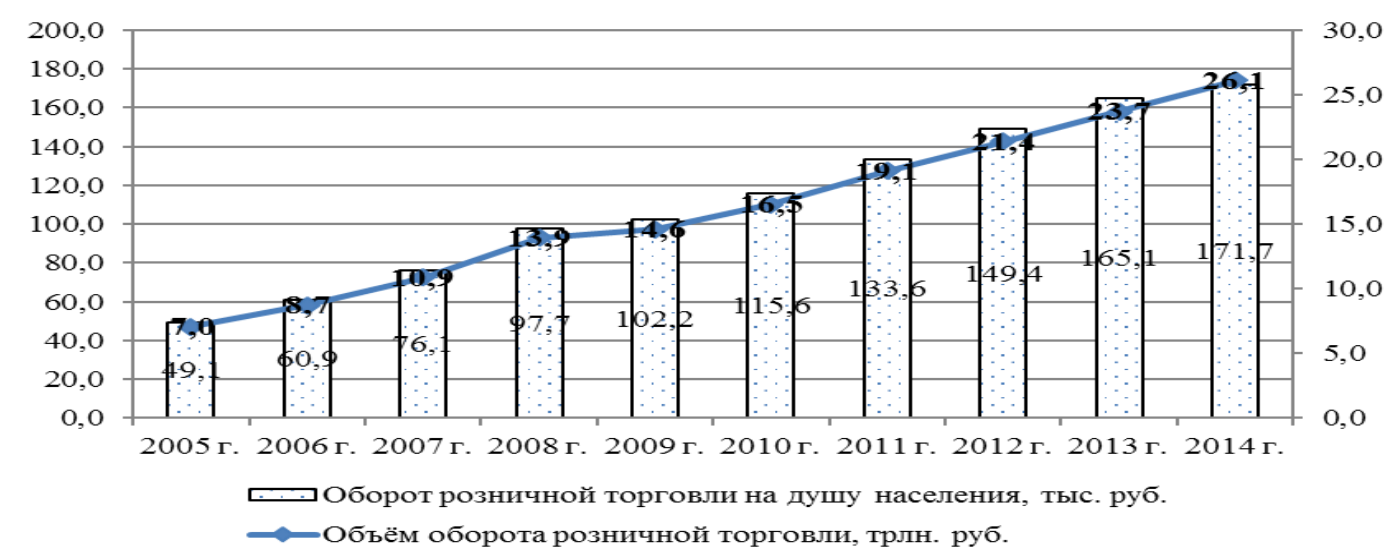

Рисунок 1. Динамика абсолютных и относительных объемов розничной торговли в России за 2005-2014 гг².

\section{Изменившаяся роль крупного ритейла в современной России}

В условиях, по сути, беспрецедентных для «новой» истории России, а также развитых стран, темпов роста экономики и всех рыночных сегментов, возникла необходимость качественного обслуживания и реализации значительного спроса населения наиболее эффективными методами. Субъектом экономики, сумевшим справиться с новыми вызовами и запросами рынков стали крупные розничные торговые сети. Их исследованию и анализу посвящены многие отечественные и зарубежные исследования (Гусакова, 2014; Попова, 2014; Фетисова, 2009; Шнорр, 2013; Щербаков, Горба, 2014; Bоylea, Lathropb, 2013; Braaka, Deleersnyderb, Geyskensb, Dekimpeb, 2013; Braaka, Geyskensb, Dekimpeb, 2014; Choia, Coughlanb, 2006; DelVecchio, 2001; Mejria, Bhatlib, 2014; Nogales, Suarez, 2005; Miquel-Romeroa, CaplliureGinera, Adame-Sánchezb, 2014; Ngobo, 2011; Sinhaa, Batrab, 1999).

\footnotetext{
${ }^{2}$ Составлено по данным сайта Федеральной службы государственной статистики: Оборот розничной торговли в расчете на душу населения по Российской Федерации; Оборот розничной торговли по Российской Федерации (годовой)
} 
Применение стандартизированных технологий управления поставками продукции, организации продаж, взаимодействия с основными производителями и мерчандайзинга позволяют данным игрокам рынка розничной продукции обеспечивать наиболее «эффективную» (удобную, комфортную) среду для потребителя, что логично определяет стабильное увеличение их значимости на российском рынке потребительской продукции - за последние годы средняя доля розничных сетей в структуре оборота розничной торговли выросла до $20 \%{ }^{3}$, при этом в некоторых регионах этот показатель варьируется от $30 \%$ до 52\% (рис. 2.).

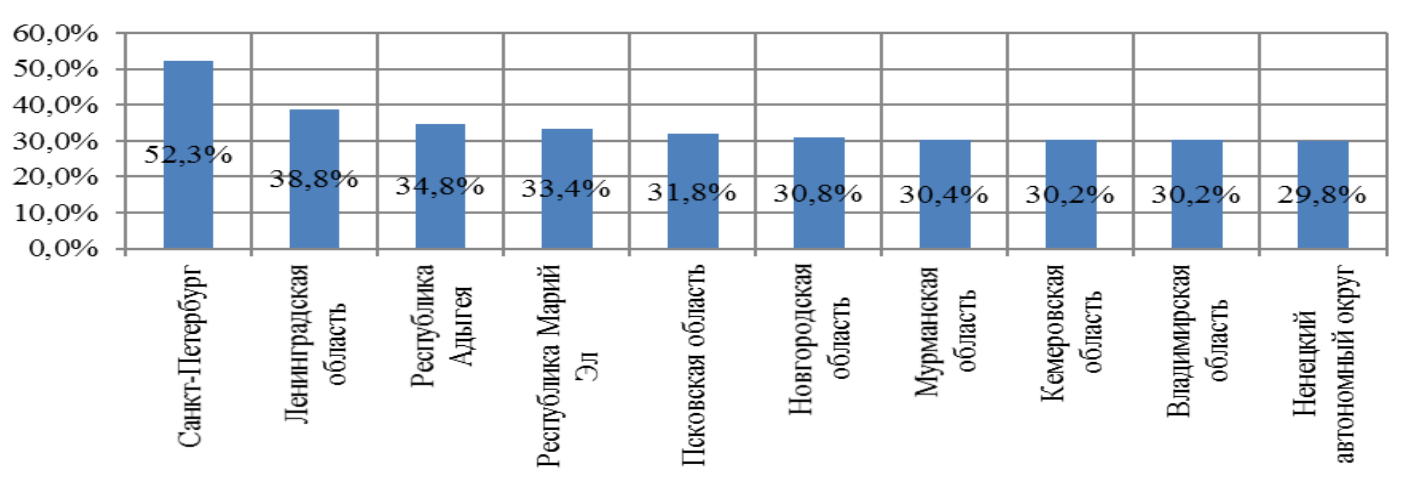

Рисунок 2. Доля розничных торговых сетей в обороте розничной торговли в различных регионах России по данным на 2013 г. ${ }^{4}$

\section{Состояние развития частных торговых марок как одного из перспективных направлений деятельности крупных ритейлеров}

Рынок продуктового ритейла ввиду его высокой емкости и динамических показателей является местом одновременного переплетения и противоборства интересов двух субъектов рынка этого рынка - производителей и продавцов (представленных торговыми сетями и магазинами). Крупнейшие торговые сети, являясь передовыми в части внедряемых организационных, маркетинговых, управленческих и прочих технологий субъектами рынка, осознали, что в текущих условиях возникает необходимость диверсификации источников дохода по различным направлениям, одним из наиболее важных в числе которых является создание собственного портфеля брендов.

\footnotetext{
${ }^{3}$ Доля розничных торговых сетей в формировании оборота розничной торговли субъектов Российской Федерации // Федеральная служба государственной статистики.

${ }^{4}$ Там же.
} 
Частные торговые марки традиционно рассматриваются как продукция, производимая по заказу розничной торговой сети либо самой сетью и предназначенная для продвижения в рамках этой сети 5 .

Стоит отметить, что концепция, ориентации на формирование портфеля частных торговых марок успешно развивается на зарубежных рынках уже многие годы, а доля частных торговых марок в выручке ведущих предприятий FMCG-рынка существенно выше, чем значение аналогичного показателя в России. Так, согласно данным международного исследовательского агентства Nielsen, доля частных торговых марок в выручке компаний в России по данным на 2013 г. Хоть и выросла, но составляет, в среднем, порядка 6\%. При этом, в большинстве европейских стран она выше $20 \%$ (рис. 3 ).

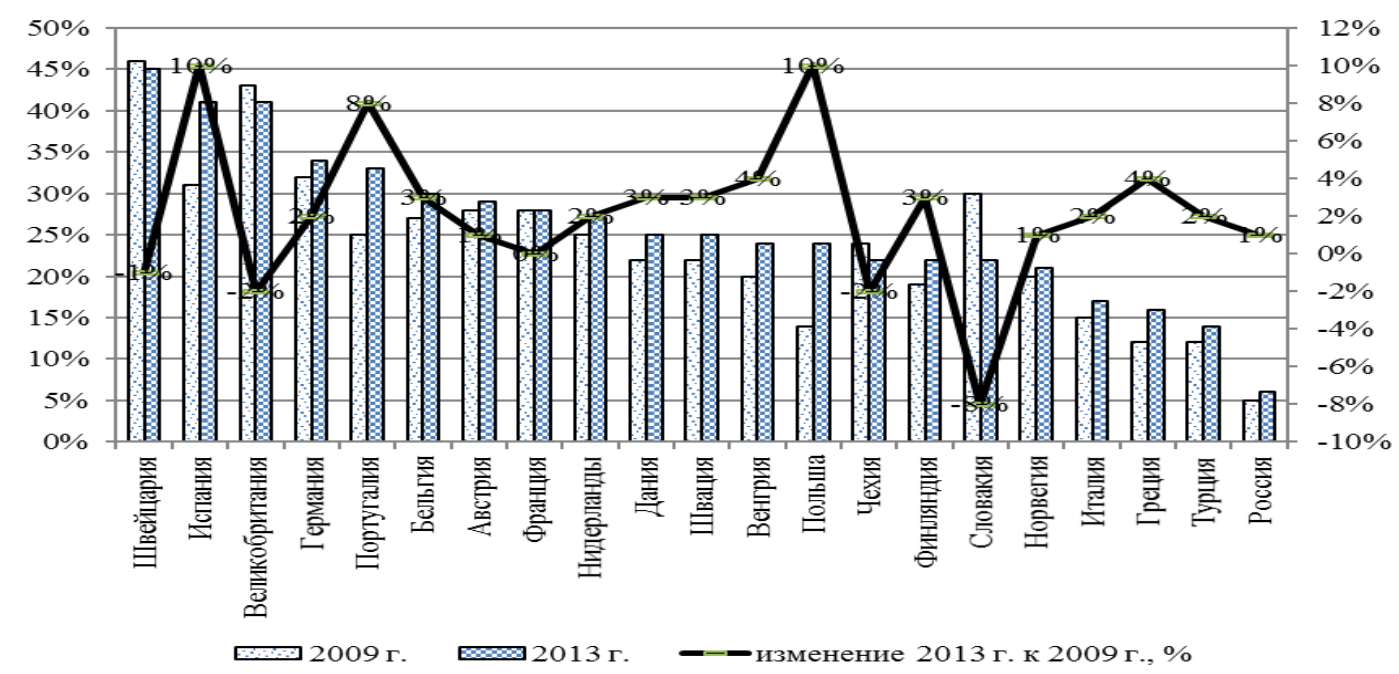

Рисунок 3. Изменение доли собственных торговых марок в торговых сетях ведущих зарубежных стран в 2013 г. по сравнению с 2009 г. ${ }^{6}$

\section{Особенности восприятия частных торговыхх марок потребителями}

Как показывают глобальные исследования, большая часть потребителей из различных стран и регионов мира относятся позитивно к частным торговым маркам торговых сетей (рис. 4).

${ }^{5}$ Рейтинг «INFOLine Private Label Profi» // Infoline; Розничные сети FMCG в России 2014 + актуальный прогноз развития в 2015-2017гг. // РБК.research; Годовой отчет X5 Retail Group 2013 // X5 Retail Group; Оборот розничной торговли по Российской Федерации (годовой) // Федеральная служба государственной статистики.

${ }^{6}$ The state of private label around the world // Nielsen. 


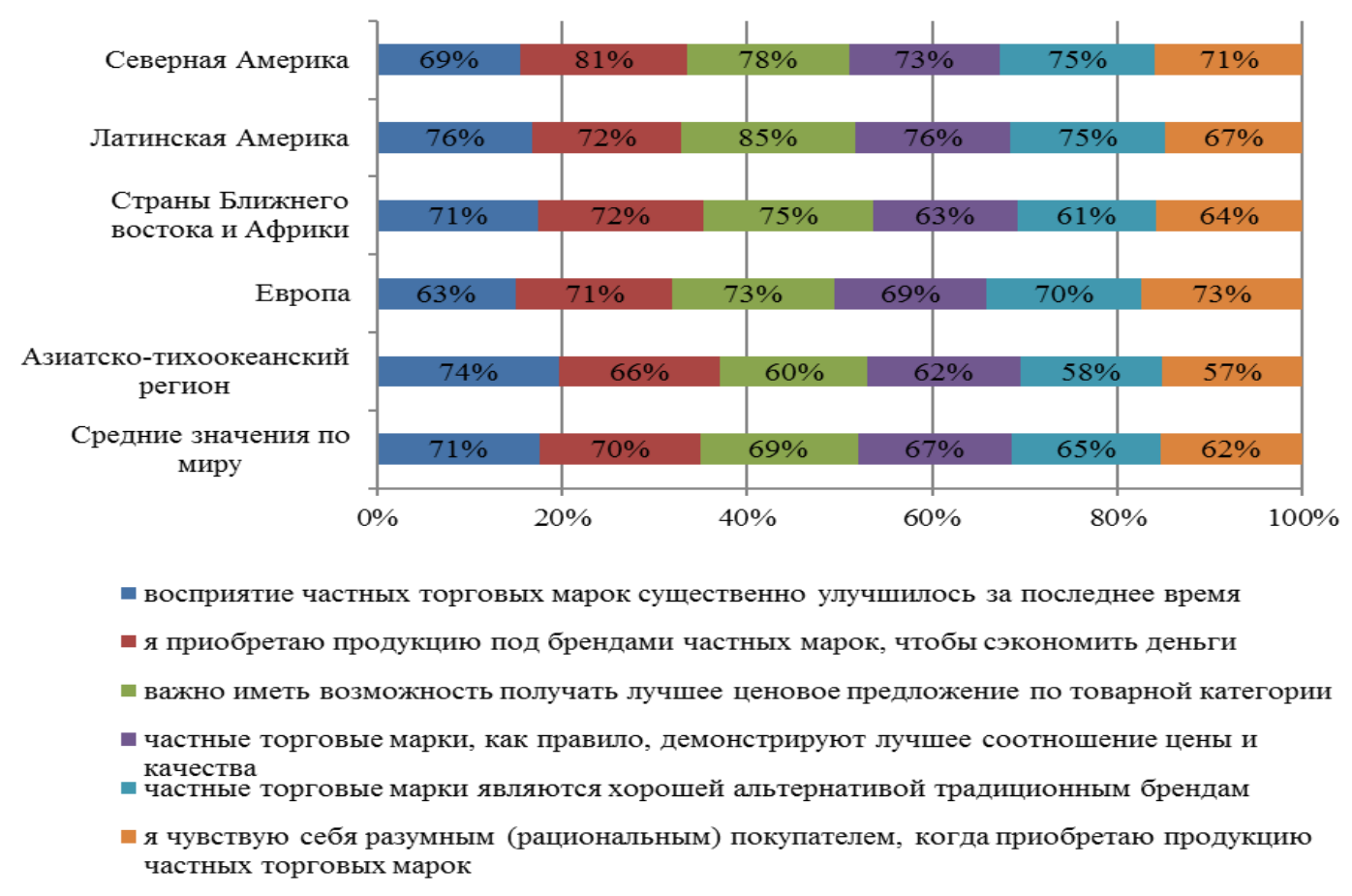

Рисунок 4. Отношение потребителей к частным торговым маркам по различным регионам мира по данным на 2014 г. (процент респондентов, которые отчасти или в большей степени согласны с предложенным утверждением) ${ }^{7}$

Таким образом, в целом отношение к частным торговым маркам, независимо от территории, является скорее позитивным, что свидетельствует о значительных перспективах данного сегмента крупных ритейлеров.

\section{Стратегические перспективы развития частных торговых марок российских ритейлеров с учетом зарубежного опыта}

Как было указано ранее, одной из основных тенденций последних лет в ведущих европейских странах является увеличение доли частных торговых марок в совокупной выручке розничных сетей. Низкая доля частных торговых марок в продажах предприятий российского FMCG-сектора объясняется несколькими причинами:

- относительно недолгой историей развития данного коммерческого направления в России, в сравнении с более богатыми

\footnotetext{
${ }^{7}$ The state of private label around the world // Nielsen.
} 
бизнес-традициями и опытом осуществления деятельности в секторе FMCG в зарубежных странах;

- $\quad$ пока еще относительно низкой долей крупнейших торговых сетей в совокупном розничном обороте в России в сравнении с зарубежными странами.

Вместе с тем, несмотря на более низкую среднюю долю частных торговых марок в российском секторе FMCG-продаж, в крупнейших торговых сетях страны, эта доля, в целом, с каждым годом приближается к среднеотраслевым значениям в зарубежных странах (рис. 5).

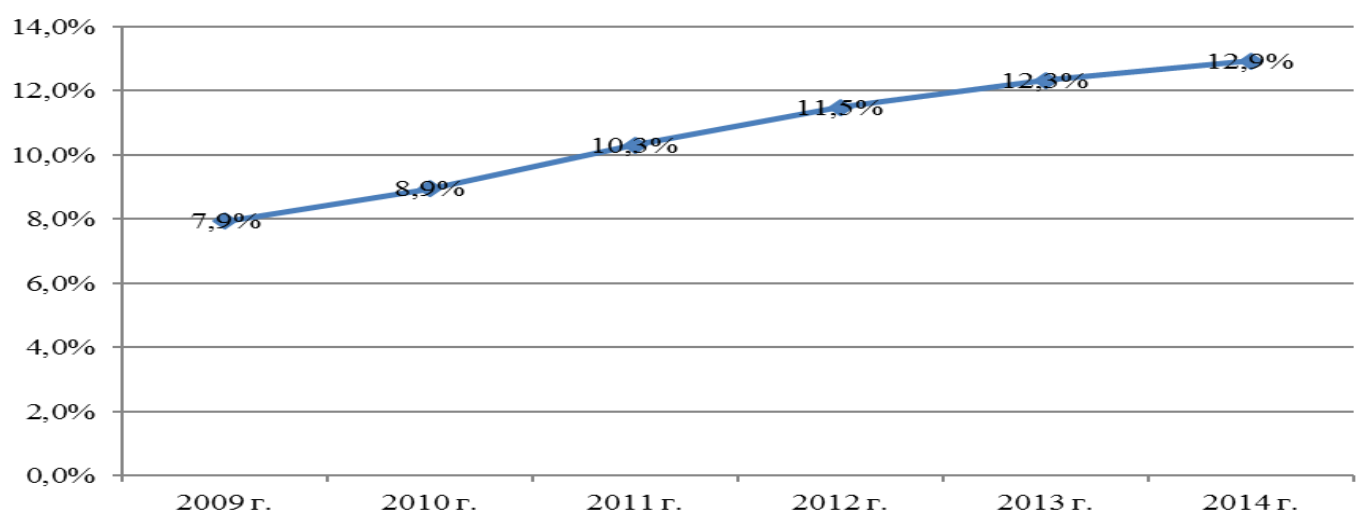

Рисунок 5. Доля частных торговых марок в выручке крупнейших российских ритейлеров за 2009-2014 гг. (по компаниям «Магнит», «X5 ритейл», «Дикси», «Лента», «Ашан», «Метро») 8

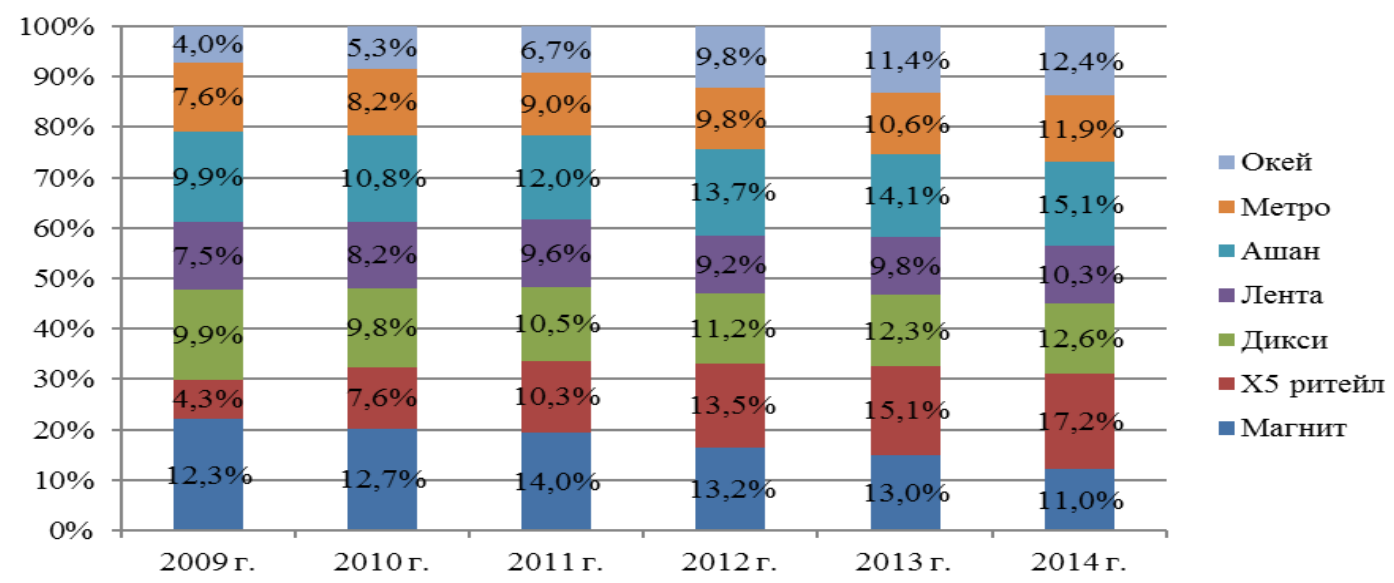

Рисунок 6. Изменение доли продаж частных торговых марок в совокупной выручке крупнейших российских ритейлеров за 2009-2014 гг. ${ }^{9}$

8 Презентация по операционным результатам за 2014 г. // Магнит; Годовые отчеты // X5 Retail Group; Презентации // Дикси; Презентации компаний // Лента.

9 Маркетинговые исследования РБК. Research: Розничные сети FMCG в России $2014+$ актуальный прогноз развития в 2015-2017гг.; Розничные торговые сети по продаже продуктов питания (FMCG) в России 2014 
Анализируя изменение доли продаж частных торговых марок в совокупной выручке продаж крупнейших ритейлеров FMCG-сектора России (рис. 6), можно сделать следующие выводы:

- $\quad$ за рассматриваемый период наблюдается разнонаправленная динамика представленности собственных торговых марок в ассортименте крупнейших сетей, что обусловило соответствующие тенденции в части значений доли реализации продукции под собственными марками в совокупной выручке крупнейших российских ритейлеров;

- в целом стратегия большей части крупнейших ритейлеров России направлена на увеличение собственных торговых марок как в ассортименте, так и в совокупной выручке;

- большинство крупнейших ритейлеров России в FMCGсекторе увеличило долю продаж продукции под частными марками в совокупной выручке рассматриваемого типа торговых предприятий, при этом не наблюдается четкой взаимосвязи между объемами выручки и долей частных торговых марок в продажах той или иной сети.

Анализируя текущую ситуацию и планы крупнейших российских ритейлеров в части формирования и продвижения портфеля частных торговых марок, можно указать на следующие наиболее важные тренды, которые проявляются в последние годы и будут определять стратегические перспективы развития частных торговых марок в России в средне- и долгосрочный период:

- крупнейшие российские ритейлеры стремятся охватить собственными торговыми марками продукцию широких товарных категорий - не обязательно, что основные акценты делаются на товарные категории эконом-класса, ритейлеры активно выходят также на продовольственную продукцию премиум-класса (к примеру, сеть X5 Retail к концу 2013 г. из 2000 наименований товаров, продвигаемых под собственной торговой маркой, 200 реализовывала в премиум-сегменте ${ }^{10}$ ); - крупнейшие ритейлеры, называя одними из основных проблем и факторов, сдерживающих широкое внедрение продукции собственных брендов, производственные возможности производителей продукции, а также необходимость организации контроля качества, стремятся решить данные проблемы путем диверсификации отношений с поставщиками как на внутреннем, так и на внешних рынках. Помимо этого, наблюдается тренд к внедрению крупнейшими сетям внутренних

10 Годовой отчет X5 Retail Group 2013 // X5 Retail Group. 
систем мониторинга и контроля качества по всей производственной цепочки производства продукции, входящей в портфель собственных брендов;

- в целом наблюдается общее увеличение инвестиционной активности крупнейших торговых сетей в направлении повышения представленности в их ассортименте продуктов под собственными торговыми марками и стремление довести долю продаж данной продукции в совокупной выручке до средневропейских показателей.

\section{Основные выводы:}

1. В исследовании проведен обзор основных тенденций национальной экономики, выраженных в оценке динамики изменения ключевых макроэкономических показателей. Определена изменяющаяся экономическая роль рынка розничных товаров на современном этапе.

2. В ходе анализа обозначено место и объемы деятельности крупнейших розничных ритейлеров на FMCG-рынке России.

3. Уточнена роль частных торговых марок в стратегии развития крупнейших ритейлеров России.

4. Выявлены основные тенденции восприятия и развития частных торговых марок как на зарубежных рынках, так и на российском FMCG-рынке. Определены стратегические перспективы и потенциал частных торговых марок в России.

В заключение, в контексте задач данной статьи, отметим, что на сегодняшний день в российской теории и практике управления маркетингом на FMCG-рынке актуализируются вопросы создания и эффективного управления частными торговыми марками, что обусловлено низкой степенью проработанности данной проблематики применительно к специфике российских условий. В частности, требуют развития следующие аспекты рассматриваемой проблематики:

- оценка и систематизация факторов, определяющих успех продвижения частных торговых марок;

- исследования особенностей потребительского поведения и моделей выбора частных марок в зависимости от тех или иных факторов; - исследования восприятия частных торговых марок в зависимости от различных условий (товарной категории, географических, экономических социально-культурных и прочих условий); 
- вопросы разработки ассортиментной стратегии (портфеля частных торговых марок);

- формирование политики ценообразования для частных торговых марок;

- вопросы разработки и внедрения технологий мерчандайзинга, а также их адаптации к задачам розничных сетей при продвижении частных торговых марок;

- вопросы формирования технологий брендинга и позиционирования частных торговых марок;

- оценка эффективности продвижения частных торговых марок розничными сетями.

\section{ИСТОчнИКИ:}

Гусакова, Е.П. (2014). Собственная торговая марка как фактор повышения конкурентоспособности торговых розничных сетей. Политематический сетевой электронный научный журнал Кубанского государственного аграрного университета, 99, 1-8.

Васильев, Г.А. Романов, А.А. Поляков, В.А. (2010). Маркетинг розничного торгового предприятия. М.: Вузовский учебник.

Старов, С.А. (2013). Управление собственными торговыми марками розничных сетей. СПб: Изд-во «Высшая школа менеджмента», 2013.

Парамонова, Т.Н., Красюк, И.Н., Лукашевич, В.В. (2013). Маркетинг торгового предприятия. М.: Дашков и К․

Попова, И.Н. (2014). Алгоритм формирования и поддержания бренда розничной торговой сети. Интернет-журнал Науковедение, 2, 1-12.

Фетисова, О.В. (2009). Современные тенденции развития мировой розничной торговли. Вестник Волгоградского государственного университета. Серия 3: Экономика. Экология, 2, 61-69.

Шнорр, Ж.П. (2013). Современные тенденции и особенности развития отечественного сетевого ритейла. Вестник Астраханского государственного технического университета. Серия: Экономика, 2, 138-147.

Щербаков, В.В., Горба, Л.К. (2014). Стратегические приоритеты развития собственных торговых марок розничных сетевых операторов. Вестник Южно-Уральского государственного университета. Серия: Экономика и менеджмент, 8(3), 106-112.

Boylea, P. J., Lathropb, E. S. (2013). The value of private label brands to U.S. consumers: An objective and subjective assessment. Journal of Retailing and Consumer Services, 20(1), 80-86. doi:10.1016/j.jretconser.2012.10.008

Braaka, A. ter, Deleersnyderb, B., Geyskensb, I., Dekimpeb, M. G. (2013). Does private-label production by national-brand manufacturers create discounter goodwill? International Journal of Research in Marketing, 30(4), 343-357. doi:10.1016/j.jjresmar.2013.03.006 
Braaka, A. ter, Geyskensb, I., Dekimpeb, M. G. (2014). Taking private labels upmarket: Empirical generalizations on category drivers of premium private label introductions. Journal of Retailing, 90(2), 125-140. doi:10.1016/j.jretai.2014.01.003

Choia, S. C., Coughlanb, A. T. (2006). Private label positioning: Quality versus feature differentiation from the national brand. Journal of Retailing, 82(2), 79-93. doi:10.1016/j.jretai.2006.02.005

DelVecchio, D. (2001). Consumer perceptions of private label quality: the role of product category characteristics and consumer use of heuristics. Journal of Retailing and Consumer Services, 8(5), 239-249. doi:10.1016/\$0969-6989(00)00030-8

Mejria, C. A., Bhatlib, D. (2014). CSR: Consumer responses to the social quality of private labels. Journal of Retailing and Consumer Services, 21(3), 357-363. doi:10.1016/j.jretconser.2013.08.001

Nogales, A. F., Suarez, M. G. (2005). Shelf space management of private labels: a case study in Spanish retailing. Journal of Retailing and Consumer Services, 12(3), 205-216. doi:10.1016/j.jretconser.2004.06.004

Miquel-Romeroa, M. J., Caplliure-Ginera, E. M., Adame-Sánchezb, C. (2014). Relationship marketing management: Its importance in private label extension. Journal of Business Research, 67(5), 667-672. doi:10.1016/j.jbusres.2013.11.025

Ngobo, P.-V. (2011). Private label share, branding strategy and store loyalty. Journal of Retailing and Consumer Services, 18(4), 259-270. doi:10.1016/j.jretconser.2010.11.007

Sinhaa, I., Batrab, R. (1999). The effect of consumer price consciousness on private label purchase. International Journal of Research in Marketing, 16(3), 237-251. doi:10.1016/S0167-8116(99)00013-0 
Artyom A. Doboni, Postgraduate student of the Chair of corporate economics and business of St. Petersburg State University

\section{Private trademarks: perception, role and strategic prospects of the development under present conditions}

ABSTRACT:

The article touches upon the main trends in the modern economy with regard to the development of the retail market and the market of FMCG-products. The changed role of the largest retail networks (retailers) in the segment of realization of FMCG-products has been substantiated. The role of private trademarks in the development strategy for the largest retailers of Russia has been specified. The main trends of private trademarks development have been revealed as on foreign markets as on the Russian FMCG-market. The strategic perspectives of private trademarks development in Russia have been substantiated.

KEYWORDS: private trademarks, trends, own trademarks, retail, FMCG-market, retail networks 